\title{
Notizen aus der tannaïtischen Literatur über das Geschlecht der hebräischen Hauptwörter.
}

\author{
Von Dr. H. Rosenberg.
}

Vorliegende Notizen schließen sich meinem Aufsatze in ZAW XXV, 325-339 eng an. Dort war ich bemüht, ALBRECHTs Abhandlung: "Das Geschlecht der hebr. Hauptwörter" (in ZAW XV. und XVI. Jahrgang) durch Vorführung des für das Bibl.-Hebräische wichtigsten Materiales aus der Mišna zu ergänzen. Hier geschieht dasselbe durch Vorführung des betreffenden Materiales aus der übrigen tannaïtischen Literatur.

Zur Textkritik benutzte ich: zur Tosefta die Editio ZUCKERMANDEL nach der Erfurter und Wiener Handschrift, Pasewalk 1880; die Editio des Alfasi Vend. 152I (Die Tosefta ist in allen Alfasi-Ausgaben im Anhange beigedruckt); AlfasI Sabionetta 1554; Alfasi Wilna 1870 mit textkritischen Noten von ELIA aus Wilna. Zur Mechilta: Editio princeps Konstantinopel 1515, Editio FriedmanN Wien 1870. Zum Sifra: Editio princeps Vend. I 545, Editio WeIss Wien I862. Zum Sifré: Editio princeps. Vend. I 546, Editio FrIEDMANN Wien 1864.

Ich zitiere die Tosefta nach Traktat und Perek, in runden Klammern gebe ich die Zahl der Seite und Zeile von Zuckermandels Ausgabe an. Die halachischen Midraschim zitiere ich nach Kapitel und Vers des. Pentateuchs, welchen jeweilen der Midraš angehört, resp. die betreffende Belegstelle entnommen ist. In runden Klammen gebe ich die Zahl der. Seite und Zeile der Ausgaben von WeIsS und FrIEDMaNN an.

Für „belegt“ und „nicht belegt“ sind die Abkürzungen „b.“ und „n. b." gebraucht.

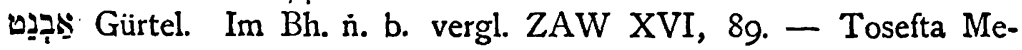
nahot I. (ZUCKERMANDEL 513 7) masc.

Maִ Mauerbau. Im Bh. n. b. vergl. ZAW XVI, 83. - Tosefta Menahot XIII (ZUCKERMANDEL 533 38) masc. 
Qְד Gedrehte Fäden. Im Bh. n. b. vergl. ZAW XVI, 97. - Sifré zu Dtn 2212 (Editio FRIEDMANN II $7^{2}$ 17) masc.

ๆ? Im Bh. (Wölbung) n. b. vergl. ZAW XVI, 72 und XXV, 329. Tosefta Sebaḥim VII (ZuCKERMANDEL 489 2I) in der Bedeutung Flügel fem.

Dִד Der eiserne Stachel an der Spitze des Ochsensteckens. Im Bh. n. b. vergl. ZAW XVI, 90. - Tosefta Sota VII (ZUCKeRMANDEL 307 13 15) und an anderen Stellen masc.

םำ Süden. Im Bh. n. b. vergl. ZAW XVI, 42. - Sifré zu Dtn 343 (Editio FriedManN $149^{2}$ 33) masc.

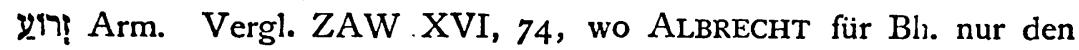
weiblichen Gebrauch gelten läßt. Vergl. dagegen ED. KöNIG: „Lehrgebäude der Hebr. Sprache“ Schlußteil Seite 165. - Tosefta Šabbat IX (ZUCKERMANDEL I2I II) masc.; Tosefta Hullin XI (ZUCKERMANDEL, 5 I I $257)$ masc.

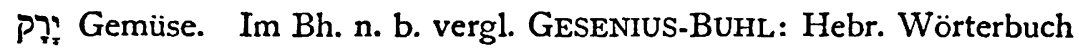
14. Auflage. - Tosefta Baba-Meșia IX (ZuCKermandel 39I 18) masc.

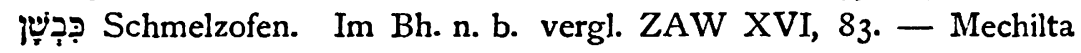
zu Ex 19 i8 (Editio FriedmanN 65 22) masc.

רַּ Knäul, Ball. Im Bh. n. b. vergl. ZAW XVI, 93. - Tosefta Šabbat X (ZUCKERMANDEL I2I 28) fem. כדור קטנה כנגון אילו שמשחקים בכדוּר ברשות הרבים וייצאת הכדור . מתחת ידו של אחר מהם

כָָּ Lende. Im Bh. n. b. ZAW XVI, 77. - Tosefta Bekorot IV (ZUCKERMANDEL 539 10) masc.

פַָ Safran. Im Bh. n. b. vergl. ZAW XVI, I06. - Tosefta Ma'aser Šeni I (ZUCKERMANDEL 87 19) masc.

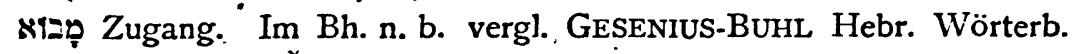
14. Aufi. - Tosefta Šabbat I (ZuCKermandel $\mathrm{I}_{\mathrm{O}} 4$ u. ro) masc.

Añ Lager. Vergl. ZAW XVI, 52, wo ALBRECHT für Bh. nur den männlichen Gebrauch gelten läßt, vẹrgl. dagegen ED. KöNIG: Lehrgebäude der Hebr. Sprache, Schlußteil S. 174. - Tosefta Erubin II (ZUCKERMANDEL I 40 2I) fem.; Tosefta III (ZUCKERMANDEL I42 I4) fem. - Sifra zu Lev 412 (Editio WeIss Seite $18^{b}$ Spalte 2 Zeile 8) fem.

מִכְנִם Unterbeinkleider. Vergl. ZAW XVI, 97, wo AlBRECHT für Bh.

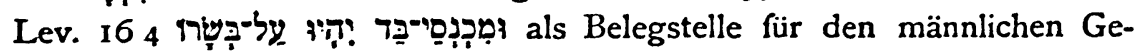
brauch zitiert, das Impf. 3. pl. beweist jedoch den männlichen Gebrauch nicht unbedingt, vergl. GESENIUS-KaUTZSCH Hebr. Grammatik 27 $\$ 145^{\text {p }}$. - Tosefta Menahot I (ZuCKermandel 513 7) fem. שתי מבנסים. 
מִלֵ Salz. Im Bh. n. b. vergl. ZAW XVI, 108. - Tosefta Menahot IX (ZuCKermandeL 526 26f.) fem. מלח ו מלח ס מלומית - Sifra zu Lev 213

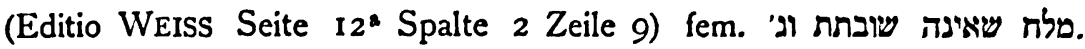
Tosefta Menahot VI (ZUCKeRMandeL 519 בשלשה מקומות היתה מלח ניתנית Im Syr. ist مدسا ebenfalls fem., vergl. NöldEke Syr. Grammatik $\int 84$.

†I Zweig. Im Bh. n. b. vergl, Gesenius-BuHL: Hebr. Wörtb. 14. Auf. - Kilajim III (ZuCKeRMANDEL 77 6) masc.

נָכָכ Nachkommen. Im Bh. n. b. - Mechilta zu Ex 1317 (Editio FRIEDMANN $23^{b}$ 20) masc.

J Zeichen. Im Bh. n. b. vergl. ZAW XVI, 92. - Sifré zu Num 255 (Editio FRIEDMANN $48^{2}$ 20) masc.

תֶָּ Laugensalz. Im Bh. n.b. vergl. ZAW XVI, 108. - Tosefta Nidda -VIII (ZuckermandeL 6509) fem. נתר ו" נתר הלכסנדרית.

ע. Wolke. Im Bh. ist masc. und fem. belegt. AlBRECHT ZAW $\mathrm{XV}, 323$ will jedoch bloß den männlichen Gebrauch gelten lassen, vergl. dagegen KöNIG: Lehrgebäude der hebr. Sprache, Schluliteil S. 163. Tosefta Sota III (ZUCKermandel 2984 4) fem. עב קטנה אדור בתוכה. Me-

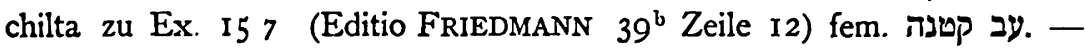
Sifré zu Dtn I I II (Editio Friedmann Seite $7^{\mathrm{a}}$ Zeile 29) fem. שהיו עבים מקיפות אותה ומשקות אותה.

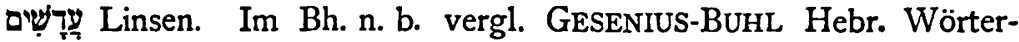
buch I4. Aufl. - Tosefta Ma'aser-Rišon III (ZuCKermandel 85 3I) masc. עדשים מצריים.

עִ עִרִבִ Bachweiden. Im Bh. masc. (ZAW XVI, I04) mit vorangehendem Verbum b., was nicht unbedingt den männlichen Gebrauch beweist, vergl. GeseniUS-KaUTZSCH Hebr. Grammatik $\ 145^{\circ}$. - Sifra zu Lev $234^{\circ}$ (Editio WeIss Seite Io2b Spalte 2 Zeile 9, II, I4) fem. ערבי נחל שתים.

עִ Wildesel. Im Bh. n. b. vergl. ZAW XVI, 67. - Tosefta Berakot III (ZUCKERMANDEL 86) masc.

חק Depositum. Im Bh. n. b. vergl. GeSEnIUS-BuHL: Hebr. Wörterbuch 14. Aufl. - Sifra zu Lev 5 21 (Editio WeIsS Seite $27^{\mathrm{b}}$ Spalte 2 Zeile II) masc.

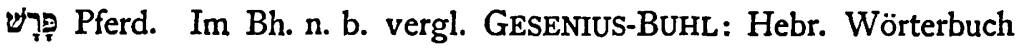
14. Aufl. - Sifra zu Lev 2633 (Editio WeISS $112^{a}$ Spalte 2 Zeile 15) masc.

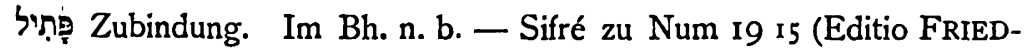
MANN Seite $45^{b}$ 5) masc.

צִבָָ Zusammenhangendes Paar. Im Bh. n. b. vergl. Gesenius-BuHL: Hebr. Wörterb. I4. Aufl. - Tosefta Aboda-Sara III (ZuCKermandel 463 


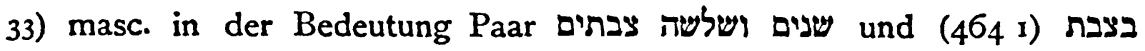
- Mišna Abot V 6 und Sifré zu Dtn 3321 (Editio FriedmanN Seite $147^{b} 3$ ) in der Bedeutung Zange fem. Das Mand. תצs und Syr. $1 A_{\partial}$ sind auch masc. und fem. vergl. NöLDEKe Mand. Gram. Seite I6I. צִִמִִ Zubindung. Im Bh. n. b. vergl. GesenIUS-BuHL: Hebr. Wörterbuch. - Sifré zu Num 19 x5 (Editio FrIEdmann Seite $45^{\circ}$ Zeile 5) 'masc.' רִ̣ Wasserstrahl, Aquädukt. Im Bh. n. b. vergl. ZAW XVI 62. Tosefta Miqvaot II (ZuCKermandel 6546) und andere Stellen masc.

קוך Affe. Im Bh. n. b. vergl. ZAW XVI, 67 letzte Zeile. - Sifra zu Lev I 37 (Editio WeIsS Seite $5^{I^{b}}$ Spalte 2 Zeile 9) masc.

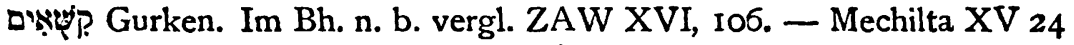
(Editio FrIedmann $47^{2}$ II) masc. את הקשאים שהיו קשים למעיהם. Tosefta Šebi it I (ZUCKERMANDEL 6I 12) masc. Der Sing. von קשואין ist in der tannaïtischen Literatur קישות und ist fem. Tosefta Terumot V (ZUCKERMANDEL 34 16) קישות של תרומה שנתעירבה.

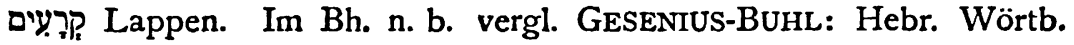
14. Auf. - Sifra zu Lev $135^{6}$ (Editio WeIss Seite 69a Spalte 2 Zeile I3) masc.

TÜ Dämon. Im Bh. n. b. vergl. ZAW XVI, 65. - Sifré zu Dtn 3217 (Editio FrIEDMANN $13^{b}$ 13) masc.

说 N. pr. Susa. Im Bh. n. b. vergl. ZAW XVI, 59. - Tosefta Megilla I (ZUCKERMANDEL 221 19) fem.

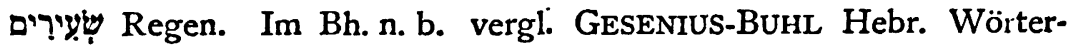
buch 14. Auflage. - Sifré zu Dtn 322 (FRIEDMANN $131^{\mathrm{b}} 152329$ 132a 13 ) masc.

לู Hügel. Im Bh. n. b. vergl. ZAW XVI, 60. - Tosefta (ZuCKERMANDEL 140 13) masc. 